John H. Barnett

\title{
Global voices, global visions International radio and television broadcasts via the Web
}

$\mathbf{T}_{\mathrm{H}}^{\mathrm{h}}$ he world is calling-are you listening? Here's how . . . Internet radio and television-tuning into information, feature, and cultural programs broadcast via the Web-piqued the interest of some educators, librarians, and instructional technologists in the 1990s. A decade ago we were still in the early days of multimedia content on the Web. Then, concerns expressed in the professional literature centered on issues of licensing, copyright, and workable business models. ${ }^{1}$

In my experiences as a reference librarian and modern languages selector trying to make Internet radio available to faculty and students, there were also information technology concerns over bandwidth usage and audio quality during that era.

What a difference a decade makes. Now with the rise of podcasting, interest in Web radio and TV programming has recently seen resurgence. Additionally, the prevalence of global issues and area studies in the academic curriculum has made international perspectives of greater value to higher education. Programming in language instruction, politics, religion, history, literature and the arts, business and economics, and the sciences are available just a few clicks from your computer-if you know where to look.

International broadcasting began in the 1920s and 1930s, with Radio Netherlands and the British Broadcasting Corporation's World Service (then known as the Empire Service) among the early adopters, transmitting programs around the globe via the shortwave radio spectrum. Both the Soviet Union (through Radio Moscow and Radio State Peace and Progress) and the United States (through the Voice of America and Radio Free Europe) also used international broadcasting as a method of communicating news and competing ideologies during the Cold War.

In more recent times, a number of religious broadcasters have appeared on shortwave radio to communicate and evangelize to an international audience. Many of these media outlets now share their programming and their messages free through the Internet, as well as through shortwave radio, cable television, and podcasts.

This article will help you find your way to some of the key sources for freely available international Internet radio and TV programming, focusing primarily on major broadcasters from outside the United States, which provide regular transmissions in English. Nonetheless, one of the benefits of tuning into Internet radio and TV is to gain access to news and knowledge of perspectives you might not normally encounter from American media outlets. This guide also offers some starting points for discovering differing viewpoints on global issues, as well.

To listen to these broadcasts, you will need a variety of plug-ins and software loaded into your computer-namely, Windows Media Player, Real Player, QuickTime, Octoshape, Flash, and iTunes.

\section{Getting started \\ - Passport to World Band Radio. Penn's Park, PA: International Broadcast- ing Services, 1988-. Published annually.}

John H. Barnett is assistant director, PALCl: Pennsylvania Academic Library Consortium, Inc., e-mail:barnett@palci. org

(c) 2008 John H. Barnett 
- World Radio TV Handbook: The Directory of Global Broadcasting. Milton Keynes, UK: WRTH Publications Limited; New York, NY: Watson-Guptill Publications, 1947- . Published annually.

These two sources represent the "old school" way of approaching the topic - print directories that provide detailed information on programming by international radio broadcasters (Passport to World Band Radio) and broadcast schedules and frequency and channel guides for tuning into broadcasts (World Radio TV Handbook). While nowadays we often don't approach a topic this way, these guides still represent two of the more authoritative sources for information on international radio and TV. If you're intent about finding broadcasts and using them for educational and informational purposes, the two resources are essential for getting you an overview of the breadth and depth available.

- RadioStationWorld: Your Global Radio Station Directory. Formerly known as TVRadioWorld, this free, Web-based resource has been in existence since 1996. RadioStationWorld provides a directory of domestic and international radio broadcasters-organized by continent, country, and community-with links to the many that transmit via the Internet. Upkeep is done by freelance contributors from around the globe. Access: http://radiostationworld.com.

- World Radio Network (WRN). Don't have time to look around for stations or figure out which is the best programming to tune into? No worries. WRN has done it all for you, providing access to some of the most well-known and highly regarded international public radio programming available from Europe, the Americas, Africa, the Middle East, Asia, and Australia. Here you can select individual radio broadcasts to listen to or tune into one of WRN's livestreams, which features continuous programming in English from stations as diverse as the Israel Broadcasting Authority, Channel Africa, Radio Sweden, Radio Australia, and KBS World Radio from Korea. Access: http://www.wrn.org.

\section{The broadcasters}

- ABC Radio Australia. ABC Radio Australia provides impressive coverage of Australian, Asian, and Pacific region affairs, economics, culture, and society. The international service of the Australian Broadcasting Corporation $(\mathrm{ABC})$ provides programming 24/7 in English and numerous Southeast Asian languages, live via the Web, audio on demand, and podcast. Some programs are repeats from Radio National, ABC's domestic radio network, but much is generated from ABC's studios in Melbourne for an international audience. Programming is diverse, including Australian history, indigenous issues, Asian business and Pacific development, health, education, and more. Access: http://www.radioaustralia.net.au/.

- All India Radio (AIR). India's national broadcaster features extensive domestic and international programming in English and national languages. Unfortunately, while AIR has broadcast via the Internet in the past (and its Web site continues to advertise the availability of live audio and on-demand programming), broadcasts are not available as of this writing. Access: http://www. allindiaradio.org/.

- BBC World Service. The "crown jewel" of all international broadcasting services, BBC World Service transmits programming in 33 languages and features round-the-clock services in English and Spanish. BBC provides the latest in world news and information, along with feature and documentary programming on British, European, and global arts, culture, and society; the sciences and the environment; and business, development, and economic issues. Recent documentary programs include "Fading Traditions," a series on ancient ways of life in the modern world; "Pain: Body, Mind, and Culture"; "Maids: The Untold Story," a look at the challenges and horrors women who work overseas as maids often face; and "Freetown Rap," an examination of the use of images and music from American rap culture during the Sierra Leonean civil war. In essence, BBC World Service lives up to its name, being 
truly global in content, which it has done for more than 75 years. Access: http://www.bbc. co.uk/worldservice.

- Channel Africa. Channel Africa is the international broadcasting service of the South African Broadcasting Corporation (SABC) and covers not only South African news, affairs, and society, but also features reporting on continentwide affairs, making it one of the few media outlets based in Africa with an international audience. Listeners can listen to livestreams, download audio files of previous broadcasts, and even watch SABC video on demand. Access: http://www.channelafrica.org.

- China Radio International (CRI). Formerly known as Radio Beijing and known to toe the official party line, CRI now offers more diversified programming in English and other languages around the clock, both live and on-demand. Content includes news, business information, and cultural features on China, as well as international affairs and development issues. And don't forget the Chinese language lessons! They're available as well. Access: http:// english.cri.cn/.

- Deutsche Welle (DW). DW broadcasts TV and radio programming from its headquarters in Cologne, Germany, in both English and German on a 24-hour basis, as well as in 30 other languages. DW excels at news, current affairs, and cultural programming, especially from the nations that comprise the European Union, but also provides significant coverage of Asian news and affairs. Radio broadcasts are available live or on demand; TV broadcasts are available in the United States only on-demand.

One highlight of DW's online services is its German language instruction, which is offered at beginner, intermediate, and advanced levels. Programming includes audio lessons, downloadable texts, and teacher's instructional guides. In addition, DW broadcasts regularly in slowly spoken German to assist language learners' comprehension. Access: http://www. dw-world.com.

- IRIB World Service. Given the current diplomatic climate, the political, religious, and anti-American rhetoric is high (you can't say you weren't forewarned), but this broadcast- ing service from the Islamic Republic of Iran (also commonly referred to as Radio Tehran) represents one of the few English-language sources for information emanating directly from the Middle East. Access: http://english. irib.ir/.

- Israel Broadcasting Authority. Navigating this site can be a challenge as the text is chiefly in Hebrew with a hard-to-find Englishlanguage menu to the side. Even then, determining where to look for actual broadcasts can be perplexing. Nonetheless, when you connect, you'll find a sampling of on-demand broadcasts of TV and radio news in English-one of the few such sources from inside the Middle East. Access: http://www.iba.org.il/; an easier to navigate site is available at http://www.israelradio.org.

- NHK World/Radio Japan Online. NHK World is the international broadcasting service of NHK, Japan's sole public broadcaster. As expected, NHK provides engaging coverage of Japanese news, current affairs, science, business, technology, and culture, as well as lessons in Japanese language. Compared with other international broadcasters, NHK World's online programming is slightly limited, with broadcasting via shortwave radio and cable TV still predominant. Nonetheless, NHK provides radio broadcasts live and on- demand and TV programming on-demand. Access: http://www. nhk.or.jp/english/.

- Radio Canada International/CBC Radio

One. America's northern neighbor provides superior, engaging coverage on Canadian society and Canadians' interrelationships with the world and one another through its regular news and current affairs programs, such as "The Link." In addition, the Canadian Broadcasting Corporation's domestic radio service, CBC Radio One, available in livestream from regional cities, features extensive current affairs and feature programs, including at present a radio serial, "Afghanada," following the lives of soldiers serving in Canada's peacekeeping forces in Afghanistan. Access: http://www.rcinet.ca/ for Radio Canada International; http://www. cbc.ca/radio for CBC Radio One.

- Radio France Internationale/Radio France (RFI). RFI broadcasts to the world 
in English, French, and more than 15 additional languages; programs can be listened to on-demand or downloaded as podcasts. Coverage of French affairs and culture is, naturellement (excellent), but RFI also features significant coverage of African and Asian affairs. Similar to Deutsche Welle, RFI also offers French language lessons both in audio and print, as well as news spoken in français facile for easy understanding. Radio France is the domestic service of French national radio and broadcasts live via the internet networks such as "Musique," "Culture," "Info," and others. Access: http:// www.rfi.fr for Radio France Internationale; http://www.radiofrance.fr for the domestic services of Radio France.

- Radio Netherlands. One of shortwave radio's earliest broadcasters, Radio Netherlands continues to make its programming available via the Internet, live, and via podcast to a global audience. The broadcaster gives excellent coverage of international issues, such as development, poverty, global warming, human rights, immigration, and international law. Though government-funded, Radio Netherlands has a strong policy of editorial independence and a reputation for objective, progressive reporting. Access: http://www. rnw.nl.

- RTVE: Radio Televisión Española. RTVE broadcasts live audio and video 24 hours a day, 7 days a week, in Spanish to an international audience via radio, cable, and the Internet. While there appears to be no English-language programming at this time, RTVE is a leading broadcaster to Latin America and, thus, is an excellent source, along with BBC Mundo, for news and information on the Spanish-speaking world. Additionally, it is one of the few broadcasters that allows you to view its 24-hour TV service free via the Internet. Access: http://www.rtve.es.

- United Nations Radio. Programs from UN Radio focus on subjects such as peace and security, development and human rights, conflict resolution, elections, health, poverty, education, and climate change, among others. There is also news coverage of events in Africa, Latin America, the Caribbean, the Middle East, and Asia. Access: http://radio. un.org/.

- Vatican Radio. Advertising itself as "the voice of the Pope and the Church in dialogue with the World," Vatican Radio broadcasts news and features on social and religious issues in 40 languages, including English. Radio is available live and on demand; some video features are also available. Access: http://www.vaticanradio.org.

- Voice of Russia. Formerly known as Radio Moscow during the Soviet era, the Voice of Russia continues to open a window from Russia to the world via programming in English on Russian and world affairs. Old habits die hard, though. While today's broadcasts are more entertaining and less propagandistic than they were during the Cold War, the Voice of Russia still exposes its state-run media roots. Access: http://www.vor.ru.

\section{Podcasts}

There are various sources for podcasts and downloadable audio and video direct from broadcasters, such as the BBC World Service, Deutsche Welle, and Radio France Internationale, as well as through content providers like the World Radio Network and iTunes.

Via iTunes, you can subscribe to radio and TV broadcasts from the BBC, CBC Radio, Deutsche Welle, NHK World, Radio France, Radio Sweden, and many others. These programs are free (for now) and can be viewed through iTunes or downloaded to portable devices. Programming is limited, though, generally consisting of much of the same domestic and international services found on the broadcasters' Web sites. In other words, you won't find the full offerings of BBC TV-you'll still have to tune in to BBC America, or take a trip across the pond for that.

\section{Notes}

1. Michael O'Leary, "Internet radio: listening to the Web," Online 23 (July/August 1999): 69-70. 